\title{
Pulse Treatment Using Azithromycin in HIV/AIDS-Associated Solitary Tumor-Like Bacillary Angiomatosis
}

\author{
Maruma $\mathrm{F}^{1^{*}}$ \\ ${ }^{1}$ Consultant, Department Of Dermatology, Universitas Academic Hospital, Bloemfontein, South Africa
}

Corresponding Author: Frans Maruma, MBChB, Dip-Hiv-Med, MMed, AAAM, FC Derm

Address: Department of Dermatology, University Of Free State, Faculty Of Health Sciences, Bloemfontein, South Africa; Email: fransmaruma2@icloud.com,marumaf@ufs.ac.za

Received date: 03 September 2020; Accepted date: 21 September 2020; Published date: 30 September 2020

Citation: Maruma F. Pulse Treatment Using Azithromycin in HIV/AIDS-Associated Solitary Tumor-Like Bacillary Angiomatosis. Asp Biomed Clin Case Rep. 2020 Sept 30;3(3):217-20.

Copyright (C) 2020 Maruma F. This is an open-access article distributed under the Creative Commons Attribution License, which permits unrestricted use, distribution, and reproduction in any medium provided the original work is properly cited.

\begin{abstract}
With the advent of the HIV/AIDS pandemic within the South Saharan region, clinicians are faced with accentuated clinical presentations of previously well-known diseases. Bacillary angiomatosis is no exception to this rule. Bacillary angiomatosis is a cutaneous and systemic bacterial infection caused by gram-negative Bartonella species. We report a case of an immunocompromised 44 years old female patient who presented with a solitary tumor-like bacillary angiomatosis that was treated successfully with azithromycin in a bi-weekly pulsed dosing regimen. This patient had a considerably large (12 x 10cm's) single lesion of the disease. The case highlights the potential that immunosuppressed patients are not only at risk of disseminated disease, but also of developing severe localized disease. Furthermore, Azithromycin pulse treatment may offer a convenient alternative as there is still no clear consensus regarding treatment protocol for using azithromycin in the treatment of cutaneous bartonellosis.
\end{abstract}

\section{Keywords}

Warthin Starry Stain, Azithromycin, Pulse Therapy, Immunocompromised, HIV/AIDS

\begin{abstract}
Abbreviations
PCR - Polymerase Chain Reaction, HIV/AIDS - Human Immune Deficiency Virus/Acquired Immuno Deficiency Syndrome

\section{Introduction}

Immunocompromised patients have a higher risk of developing Bartonella infections. The three most important Bartonella species known to cause human disease are B. bacilliformis, B. quintana, and Bartonella henselae $[1,2]$. Cats continue to be the leading reservoirs of this organism [3]. In South Africa, the prevalence of Bartonella in HIV positive patients is comparable to previously reported prevalence.

Frean et al. (2002) looked at the prevalence of Bartonella in HIV positive out-patients at several hospitals in Johannesburg and found a 10\% PCR prevalence of Bartonella [2]. Except for erythromycin, a tetracycline derivative, and gentamicin, specific data relating to dosage, frequency, and duration of using azithromycin in cutaneous bacillary angiomatosis is lacking. We report a case of successful treatment using azithromycin as pulse therapy.
\end{abstract}




\section{Case Report}

A 44 years old female patient presented to our dermatology clinic with a two months history of solitary, slow-growing, painless, and ulcerative mass on her left mid ulnar area. She was known with HIV/AIDS and had been on antiretroviral medication for 5 months and had no other comorbidities.

Clinical examination revealed a healthy-looking female with normal vital signs, no abnormal findings on general examination, and no overt stigmata of HIV associated opportunistic diseases. Examination of the lesion on the left mid-ulnar aspect of the forearm confirmed the presence of exophytic fleshy mass with surface ulceration and evidence of fresh bleeds (Fig-1). The mass measured $12 \times 10 \mathrm{~cm}$ in dimension. Focused examination of the ipsilateral epitrochlear and axillary lymph nodes revealed small rubbery lymphadenopathy of less than $1 \mathrm{~cm}$ in diameter.

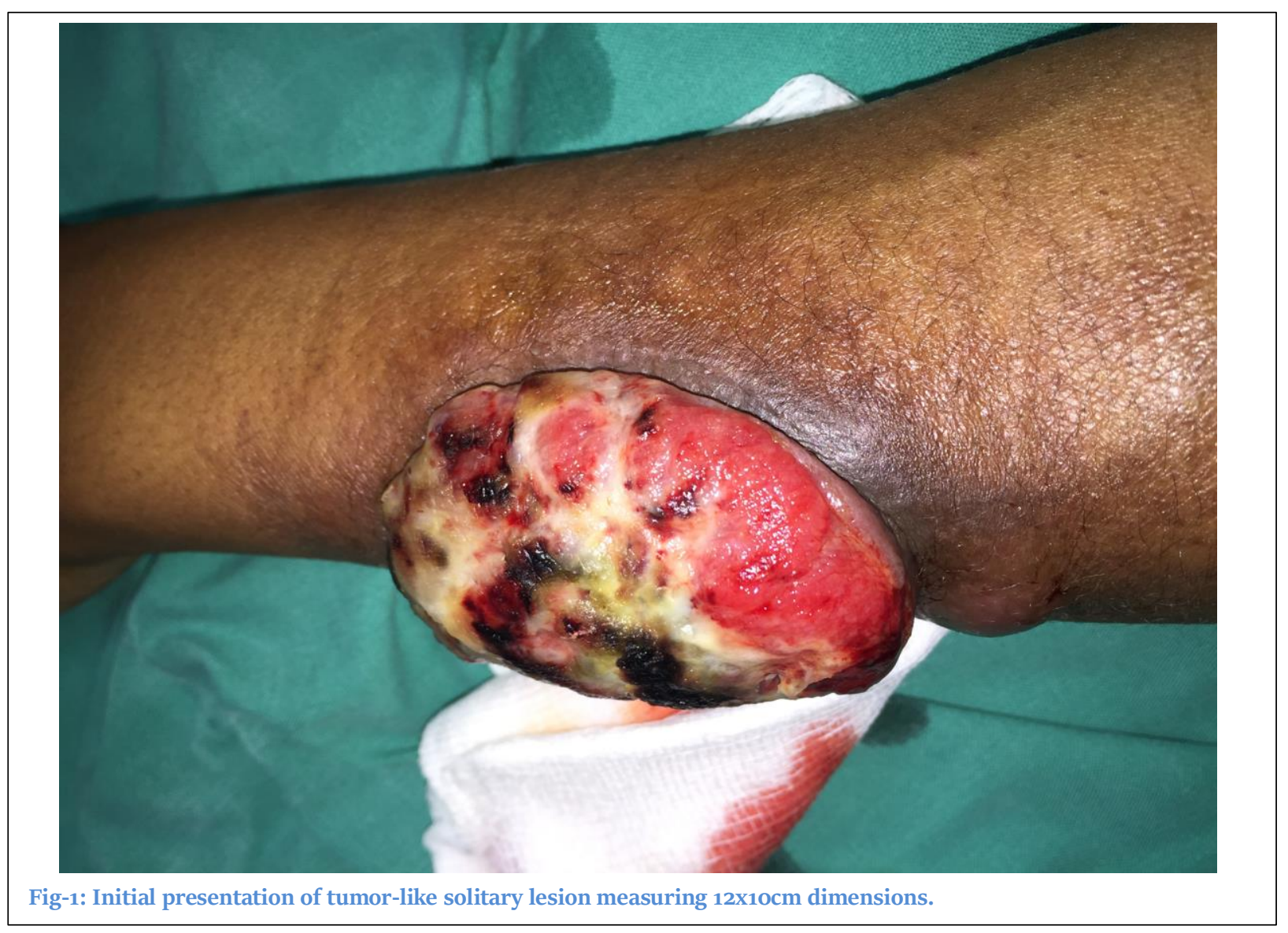

In view of the history and clinical features, the following differential diagnoses were considered, i) Kaposi Sarcoma, ii) Bacillary angiomatosis, iii) Solitary plasmablastic lymphoma, iv) Giant pyogenic granuloma, v) other cutaneous malignancies such as squamous cell carcinoma and melanoma.

An appropriate punch biopsy was performed for histopathological evaluation of the lesion. Microscopic examination of the specimen showed hyperkeratosis, acanthosis, and ulceration with underlying granulation tissue admixed with chronic inflammatory cell infiltrate. A poorly circumscribed dermal component of the lesion was composed of a proliferation of capillary size blood vessels lined in areas by polygonal epithelioid cells with eosinophilic cytoplasm. Spindle cell component, red cell extravasation karyorrhectic debris was also noted.

Immunohistochemical profiling of the lesion showed negative HHV8 and CMV, however with a positive CD34 \& CD31 within vascular walls. The presence of vascular lesion that resembles pyogenic granuloma however with numerous neutrophil karyorrhexis prompted Warthin Starry stain, but this yield was inconclusive. Finally, a PCR for Bartonella was 


\section{Case Report}

performed and demonstrated positivity within the tissue submitted.

The final diagnosis of bacillary angiomatosis was made and treatment was initiated. Owing to the unavailability of erythromycin in our province public sector, azithromycin had to be used at pulse dose: 50omg daily for 3 days every 14 days. The longer halflife of azithromycin could explain the clinical response noted in this case.

Our patient had complete resolution of the lesion within three months of starting the above-mentioned treatment regimen (Fig-2).

\section{Discussion}

Although our patient had bacillary angiomatosis, a history of 'cat scratch' was not elicited. She did report that there were no pets in her household. This raises a question of other modes of transmission other than via cats as reservoirs $[4,5]$. In this scenario, one could support authors who postulate that there could be other modes of transmission although the data is conflicting.

Clinically, the patient had an extremely large single tumor-like lesion, which represents the site of primary inoculation. As known, the severity of the Bartonella infection typically correlates with the host's immune function [6]. The case-patient was immunocompromised with a suppressed viral load and CD4 Count of 208 and this could explain the reason she contracted the infection.

In terms of treatment, erythromycin is the treatment of choice. Other effective antimicrobials include doxycycline, clarithromycin, rifampicin, and gentamicin [7-10]. We did not have erythromycin within the public health sector and the patient had reported a previous episode of fixed drug eruption due to doxycycline. We then opted to use azithromycin. The dosing and duration of treatment using azithromycin is not so clear. As such, we opted to use a pulse therapy using azithromycin 50omg daily for three days repeated every 14 days for a total of 7 dosages (3 months duration). Complete clearance was seen by week 5 as illustrated in Fig-2.

\section{Acknowledgements and Disclosures}

The author of this publication has not received any financial support and there is no conflict of interest to declare. Informed consent was obtained from the patient and ethical clearance was granted by the University Of Free State's ethics committee.

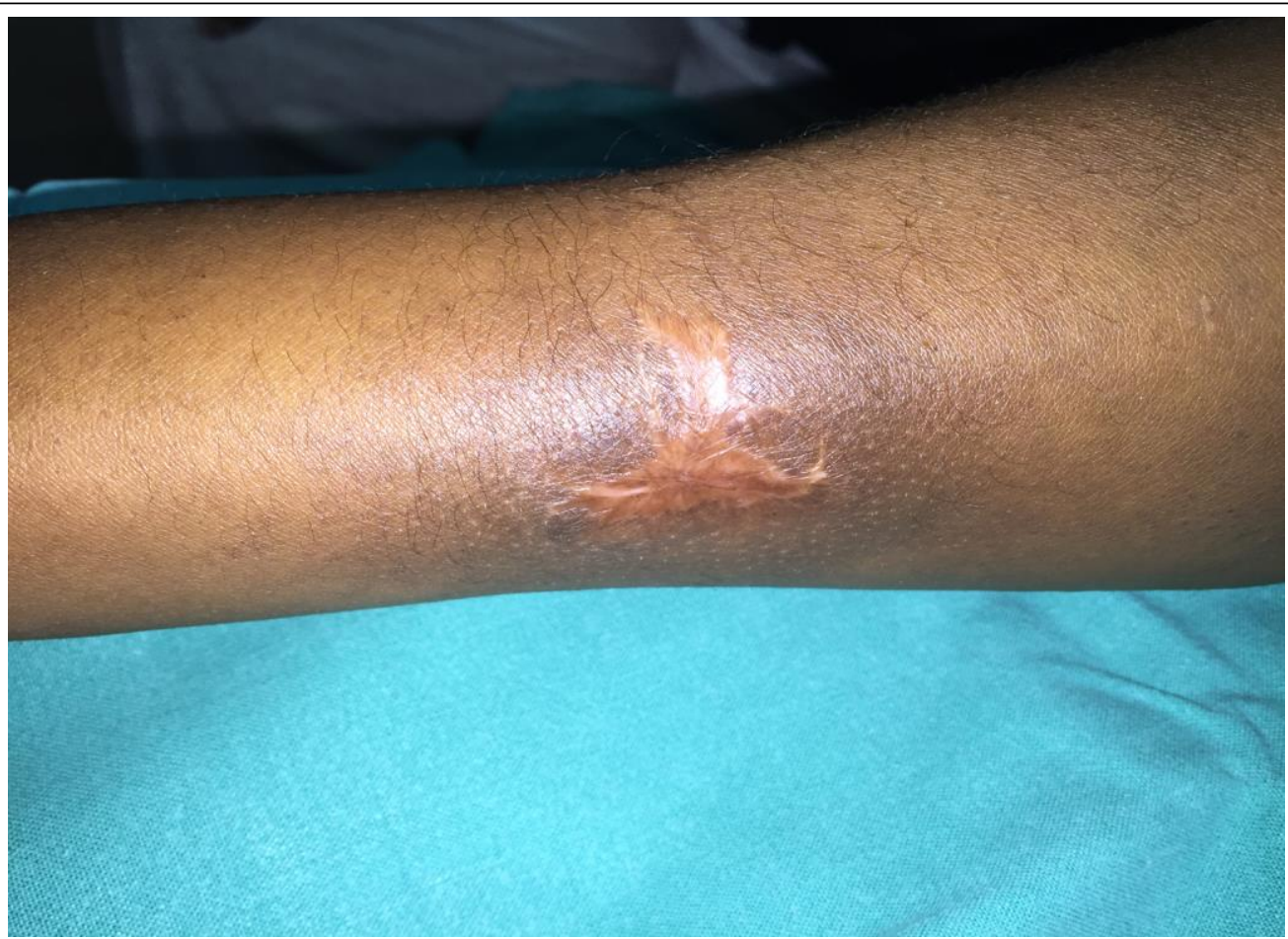

Fig-2: Week 5 of bi-weekly azithromycin pulsed treatment. 


\section{Conclusion}

In conclusion, In HIV/AIDS, bacillary angiomatosis lesions may present with larger lesion sizes of more than $10 \mathrm{~cm}$ diameter as in this case report. This case further illustrates that azithromycin may be used as pulse therapy in HIV/AIDS patients as opposed to daily dosing that may end up causing unwarranted interactions with antiretroviral treatment as well as possible hepatocellular compromise. Further studies are still needed to validate the pharmacology behind the phenomenon demonstrated through this case report.

\section{References}

[1] Trataris AN, Rossouw J, Arntzen L, Karstaedt A, Frean J. Bartonella spp. in human and animal populations in Gauteng, South Africa, from 2007 to 2009. Onderstepoort J Vet Res. 2012 Jun 20;79(2):452. [PMID: 23327372]

[2] Frean J, Arndt S, Spencer D. High rate of Bartonella henselae infection in HIV-positive outpatients in Johannesburg, South Africa. Trans R Soc Trop Med Hyg. 2002 Sep-Oct;96(5):549-50. [PMID: 12474487]

[3] Koehler JE, Glaser CA, Tappero JW. Rochalimaea henselae infection. A new zoonosis with the domestic cat as reservoir. JAMA. 1994 Feb 16;271(7):531-35. [PMID: 8301768]

[4] Telford SR 3rd, Wormser GP. Bartonella spp. Transmission by ticks not established. Emerg Infect
Dis. 2010 Mar;16(3):379-84. [PMID: 20202410]

[5] Reis C, Cote M, Le Rhun D, Lecuelle B, Levin ML, Vayssier-Taussat M, Bonnet SI. Vector competence of the tick Ixodes ricinus for transmission of Bartonella birtlesii. PLoS Negl Trop Dis. 2011;5(5):e1186. [PMID: 21655306]

[6] Resto-Ruiz S, Burgess A, Anderson BE. The role of the host immune response in pathogenesis of Bartonella henselae. DNA Cell Biol. 2003 Jun;22(6):431-40. [PMID: 12906736]

[7] Angelakis E, Raoult D. Pathogenicity and treatment of Bartonella infections. Int J Antimicrob Agents. 2014 Jul;44(1):16-25. [PMID: 24933445]

[8] Raoult D, Fournier PE, Vandenesch F, Mainardi JL, Eykyn SJ, Nash J, James E, Benoit-Lemercier C, Marrie TJ. Outcome and treatment of Bartonella endocarditis. Arch Intern Med. 2003 Jan 27;163(2):226-30. [PMID: 12546614]

[9] Rolain JM, Brouqui P, Koehler JE, Maguina C, Dolan MJ, Raoult D. Recommendations for treatment of human infections caused by Bartonella species. Antimicrob Agents Chemother. 2004 Jun;48(6):192133. [PMID: 15155180]

[10] Foucault C, Raoult D, Brouqui P. Randomized open trial of gentamicin and doxycycline for eradication of Bartonella quintana from blood in patients with chronic bacteremia. Antimicrob Agents Chemother. 2003 Jul;47(7):2204-207. [PMID:
[P 12821469] 